\title{
ANNOUNCEMENTS
}

\section{STUDIES IN SECOND LANGUAGE ACQUISITION 10:2 SPECIAL ISSUE}

The topic of this year's thematic issue is "The Evaluation of Communicative Ability." The core of the issue consists of selected papers presented at The Symposium on the Evaluation of Foreign Language Proficiency held in Bloomington, Indiana, this past spring. Although these papers focus on presenting and evaluating the ACTFL/ETS (American Council on the Teaching of Foreign Languages/Education Testing Service) oral proficiency interview and the accompanying ACTFL Proficiency Guidelines, other papers have been invited that provide alternative measures of communicative ability.

\section{PROCEEDINGS FROM THE INDIANA UNIVERSITY SYMPOSIUM ON THE EVALUATION OF FOREIGN LANGUAGE PROFICIENCY}

An international symposium on the Evaluation of Foreign Language Proficiency was held on the campus of Indiana University, Bloomington, from March 4-6, 1987. The participants included about 30 specialists from the U.S. on language testing and communicative approaches to language teaching, as well as the leading scholars in applied linguistics from nine foreign countries. The Bloomington Symposium marked the first time that proponents of the ACTFL Proficiency Guidelines and those who have expressed reservations about the enterprise met around the same table to confront the issues.

The Proceedings from the Symposium are now available for purchase. Send a check or money order for $\$ 15.25$ plus shipping $(\$ .94$, 4th class book rate in the U.S., $\$ 1.76$ for Canada; $\$ 6.28$, airmail to Europe; $\$ 8.57$, airmail to Asia; $\$ 2.16$, surface mail to Europe or Asia) made out to CREDLI to the following address:

Symposium Proceedings
CREDLI
Indiana University
602 Ballantine Hall
Bloomington, IN 47405
U.S.A.




\title{
12TH INTERNATIONAL CONFERENCE ON COMPUTATIONAL LINGUISTICS
}

August 22-27, 1988

Budapest, Hungary

\section{Call for Papers}

Sponsored by the International Committee on Computational Linguistics

Organized by the John von Neumann Society for Computing Sciences in cooperation with the Computer and Automation Institute and the Institute for Linguistics of the Hungarian Academy of Sciences

Papers are invited on substantial, original, and unpublished research on all aspects of computational linguistics, including, but not limited to:

THEORETICAL ISSUES related to linguistics, mathematics, computer science, and cognitive science

COMPUTATIONAL MODELS in phonemics, morphemics, syntax, semantics, and pragmatics, including parsing and generation, discourse, and speech acts and planning

LINGUISTIC CONTRIBUTIONS to NL dialog systems, machine and machineaided translation, speech understanding and voice output procedures, text generation, document-based information retrieval systems, building of dictionaries for humans and machines, and intelligent text editors

KNOWLEDGE REPRESENTATION AND INFERENCING, including language comprehension and automatic creation of knowledge bases from texts HARDWARE AND SOFTWARE SUPPORT for language data processing CL TOOLS FOR LANGUAGE LEARNING AND TEACHING

Authors should submit four copies of an extended abstract not exceeding seven double spaced pages plus a title page including the title, the name(s) of the author(s), complete address, a short (5-line) summary, and a specification of the topic area to the following address:

\author{
Dr. Eva Hajicova \\ Charles University \\ Faculty of Mathematics and Linguistics \\ Malostranské n.25 \\ 118 oo Praha 1 \\ CZECHOSLOVAKIA
}

Abstracts must be received no later than 10 December 1987.

Inquiries about the program and exhibitions should be directed to COLING 99 Secretariat, c/o MTESZ CONGRESS BUREAU, H-1055, Budapest, Kossuth tér 6-8, HUNGARY. 


\section{SECOND LANGUAGE RESEARCH FORUM HONOLULU}

The University of Hawaii at Manoa will host the eighth Second Language Research Forum (SLRF) March 3-6, 1988.

Plenary Speakers: Susan Gass (Michigan State University)

Eric Kellerman (University of Nijmegen)

Barry McLaughlin (University of California, Santa Cruz)

Richard Schmidt (University of Hawaii, Manoa)

Papers will be presented in areas of SLA, including Bilingualism, SL Classroom Processes, Discourse Analysis, Ethnography of SLA, Interlanguage Universals, and Transfer.

For information, contact:

Janice Cook or Toshiyuki Doi, Co-chairs

SLRF '88, Department of ESL

University of Hawaii at Manoa

1890 East-West Road

Honolulu, HI 96822

U.S.A.

\section{LANGUAGE AND EDUCATION \\ Call for Papers}

Editor: $\quad$ David Corson

Associale Editor: Viv Edwards

Review Editor: Jenny Cheshire

The primary aim of the journal is to provide a forum for the discussion of those topics and issues in the language disciplines that have a bearing on theory and practice in education.

Papers should normally not exceed 7,000 words and should be typed double spaced on A4 paper. Three copies of the manuscript should be submitted to:

Multilingual Matters Limited

Bank House

8a Hill Road

Clevedon, Avon

England BS21 7HH

Telephone: (0272) 876519 


\title{
LANGUAGE, CULTURE, AND CURRICULUM
}

\author{
Call for Papers
}

Executive Edilor: Eoghan MacAogain (Linguistics Institute of Ireland)

Review Editor: Padraig O'Riagain (Linguistics Institute of Ireland)

Language, Culture, and Curriculum is an international journal that publishes theoretical and empirical studies on bilingualism and multiculturalism. The focus of the journal is on the relationship between language and cultural identity and on school-based programs aimed at maintaining and developing this relationship. Minority and heritage languages are a special concern. First-language studies that have implications for multiculturalism are also welcomed.

It is a major objective of the journal to discuss the varieties of bilingual education and language maintenance programs in order to clarify the distinctive needs served by second languages and to provide practical guidelines for syllabus design and language planning.

Papers should normally not exceed 7,000 words and should include an abstract of not more than 200 words. Authorship should be indicated on a separate page in order to facilitate blind review. Four copies of the manuscript should be submitted to:

Eoghan MacAogain, Editor

Language, Culture, and Curriculum

The Linguistics Institute of Ireland

31 Fitzwilliam Place

Dublin 2, IRELAND 